\title{
Erratum to: MR colonography in inflammatory bowel disease
}

\author{
A. G. Schreyer, ${ }^{1}$ K. Scheibl, ${ }^{1}$ P. Heiss, ${ }^{1}$ S. Feuerbach, ${ }^{1}$ J. Seitz, ${ }^{1}$ H. Herfarth ${ }^{2}$ \\ ${ }^{1}$ Department of Radiology, University Hospital Regensburg, 93042 Regensburg, Germany \\ ${ }^{2}$ Department of Internal Medicine I, University Hospital Regensburg, 93042 Regensburg, Germany
}

\section{Erratum to: Abdom Imaging (2006) 31:302-307 DOI 10.1007/s00261-005-0377-6}

This article was inadvertently published a second time under DOI: 10.1007/s00261-006-9111-2. Official publication is under DOI: 10.1007/s00261-005-0377-6 appearing in Abdom Imaging (2006) 31:302-307.

The online version of the original article can be found under doi:10.1007/s00261-005-0377-6.

Correspondence to: A. G. Schreyer; email: andreas.schreyer@klinik. uni-r.de 